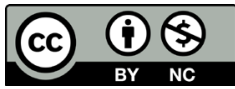

Licenciado sob uma licença Creative Commons

ISSN 2175-6058

DOI: http://dx.doi.org/10.18759/rdgf.v20i3.1787

\title{
CRÍTICA DO CONSTITUCIONALISMO E RELAÇÕES INTERNACIONAIS EM “O SENHOR EMBAIXADOR” DE ÉRICO VERÍSSIMO
}

CONSTITUTIONALISM AND INTERNATIONAL RELATIONS CRITICS IN “MISTER AMBASSADOR” BY ÉRICO VERÍSSIMO

\author{
Gustavo Oliveira Vieira
}

Valéria Ribas do Nascimento

\section{RESUMO}

O presente trabalho visa problematizar a relação interdisciplinar entre Direito e Literatura a partir do romance "O Senhor Embaixador" de Érico Veríssimo, com enfoque principal nas convergências com o constitucionalismo e as Relações Internacionais. 0 artigo é organizado em três partes, primeiro introduzindo o autor e obra, depois a abordagem do constitucionalismo e, na sequência, Relações Internacionais a partir do romance em destaque - expondo a relevância do trabalho para os dilemas jurídico-políticos da atualidade na América Latina. Quanto à perspectiva metodológica, é adequado o viés da fenomenologia, pois o Direito e as Relações Internacionais são eminentemente interpretativos, numa abordagem dialética.

Palavras-chave: Constitucionalismo. Relações Internacionais. Érico Veríssimo.

\section{ABSTRACT}

The present work aims to problematize an interdisciplinar relation between Law and Literature since the romance "Mister Ambassador" $(O$ Senhor Embaixador) wrote by Erico Veríssimo, with the main focus on the 
convergences with constitutionalism and International Relations. The article is organised in three parties, first an introduction to author and his work, then the approach on constitutionalism and International Relations throught the highlighted romance - exposing its relevance to the contemporaian juridical and political dilemas in Latin America. On the methodological perspective, the adequate bias is fonomenology, considering that Law and International Relations are emminently interpretatives, in a dialetical approach.

Key-words: Constitutionalism. International relations. Érico Veríssimo.

\section{INTRODUÇÃO}

O presente texto tem por objetivo discutir a obra "O Senhor Embaixador” de Érico Veríssimo (1905-1975), publicada em 1965, a partir de suas relações com o Direito e a Política, em especial com o constitucionalismo e as Relações Internacionais. 0 romance político tem como palco, de um lado, a capital dos Estados Unidos da América em Washington e, de outro, uma ilha ficcional chamada República de Sacramento. 0 livro tem como protagonista um recém empossado chefe da missão diplomática junto aos EUA. O Embaixador Gabriel Heliodoro Alvarado, bem como destaca um jovem diplomata, oriundo da elite de Sacramento, chamado Pablo Ortega.

Existem relações óbvias entre Literatura e Direito, pois a primeira, muitas vezes, retrata os conflitos advindos das relações processuais e das violações a direitos, com suas consequentes cargas de justiça ou injustiça. Entretanto, o contrário não é uma prática comum, já que o sistema jurídico - via de regra - não se socorre da literatura para suas decisões (NASCIMENTO; MENDONÇA, p. 280). 0 movimento Law and Literature foi iniciado nos EUA nos anos setenta, aperfeiçoando-se na seguinte década, tendo como objetivo encontrar na literatura pontos de contato que forneçam ao Direito diferentes subsídios para entender o bem e o mal, o justo e o injusto, o legal e o ilegal, dentre outros dilemas humanos, facilmente encontrados nos diferentes Tribunais, nacionais e internacionais. Via de regra, existe uma divisão metodológica para se estudar esse movimento: o Direito na Literatura, o Direito como Literatura e o Direito da Literatura. Aqui, como o estudo partirá da representação 
do Direito através de uma obra literária, será apresentada a primeira perspectiva (SCHWARTZ, 2006). Para François Ost, no livro ninguém teria ido tão longe quanto Platão, "na origem das montagens políticas e das construções jurídicas", "pôr o poeta sob tutela para preservar a integridade do dogma"(OST, 2004, p. 11).

A atualidade e a relevância da discussão sobre as implicações constitucionais da mundialização, que se debate em As reconfigurações do constitucionalismo (NASCIMENTO, 2011) e em Constitucionalismo na Mundialização (VIEIRA, 2015) tem amplo campo exploratório no romance "O Senhor Embaixador" de Érico Veríssimo pela adequada estrutura da obra literária quanto à sua sofisticada crítica social, sobre as contradições da ordem político-social-econômica dos países latinoamericanos, e a crítica da (geo)política que se define com a explicitada divisão internacional do trabalho, e do poder.

A obra apresenta a conflituosidade política de determinados regimes estatais daquela época, entre prenúncios de democracia e aspirações autoritárias. Com isso, percebe-se que a obra lança vários elementos em que é possível observar o Direito, sobretudo na relação existente entre o Direito e poder; o Direito e a democracia e as nebulosas passagens de democracias para ditaduras, ou mesmo, os processos inversos, ditaduras para democracias - livro discutido no programa Direito \& Literatura (STRECK, 2010). A República do Sacramento é uma síntese do que ocorre em vários países, principalmente da América Latina - o recorte é principalmente nas relações dos Estados Unidos com países latino-americanos.

Por isso, torna-se pertinente abordar, na sequência, alguns trechos do "Senhor Embaixador" em que são possíveis observar esses momentos históricos, impregnados pelo direito. A primeira parte do presente texto retoma o contexto do autor e sua obra, onde se desvela a sua pertinência para se pensar o Direito e as Relações Internacionais na contemporaneidade. No segundo momento do artigo o enfoque é dado à relação do que se passa em Sacramento e o constitucionalismo e, no terceiro e último, a crítica das Relações Internacionais do romance. Quanto à perspectiva metodológica, é adequado o viés da fenomenologia, pois o Direito e as Relações Internacionais não deixam de sofrer as 
contingências histórico-culturais do universo em que se integram e da interpretação a que estão submetidos.

\section{A CRÍTICA SOCIAL POR MEIO DA LIBERATURA: FATO E FICÇÃO NA OBRA DE ÉRICO VERÍSSIMO}

O "contador de histórias", como se definia o gaúcho de Cruz Alta, Érico Veríssimo, é autor de diversas obras de literatura, tanto infantil quanto adulta, que enfatizam críticas sociais, políticas e econômicas tão profundas quanto eticamente sofisticadas sobre o imaginário social, a estrutura da sociedade e o exercício do poder (e suas interações). Críticas que abordam temáticas sobre uma ampla diversidade temática, como a questão da verdade, a religião, a desigualdade social (Vidas Cruzadas, 1935), a iniquidade quanto à condição de gênero (nas personagens Ana Terra e Bibiana, da trilogia $O$ Tempo e o Vento - aliás, o autor expressa nas personagens femininas uma fortaleza que impressiona, bem como as suas mazelas ao viver em uma sociedade machista). Também são pautas recorrentes o racismo, a paz e a violência (O Prisioneiro, 1967), a democracia e a liberdade de pensamento e expressão (Incidente em Antares, 1971). São assuntos circulares na literatura do escritor que se consagrou com a trilogia "O Tempo e o Vento" - onde narra de maneira genial, sensível e historicamente precisa, a saga do Rio Grande do Sul em três grandes partes, $O$ Continente, $O$ Retrato e $O$ Arquipélago.

A obra de Érico é composta por trabalhos de ficção, com romances de cunho realista, sob cenários históricos em que se percebe uma fina sintonia entre os eventos e as pautas do período descrito e a narrativa ficcional - notadamente na segunda parte de sua obra. Tudo isso em ambientes geográficos bastante conhecidos do autor, como o interior do Rio Grande do Sul, a capital do estado, Porto Alegre, Washington onde viveu enquanto dirigiu o Departamento de Assuntos Culturais da Organização dos Estados Americanos, entre 1953 e 1956. Érico também desenvolveu trabalhos como jornalista, editor, tradutor, entre outras atividades no campo editorial. Na literatura de sua autoria o que se percebe é a busca por problematizar e responder às inquietações em 
pauta que seu zeitgeist desvelava. Indagações que seguem absolutamente relevantes na atualidade.

Além de receber diversos títulos e prêmios, como no caso do prêmio jabuti na categoria romance, pela Câmara Brasileira de Livros, pela publicação do "Senhor Embaixador" no ano de 1965, Érico também se negou a receber outros. No caso, declinou do título doutor Honoris Causa da Universidade Federal do Rio Grande do Sul, durante o período do regime militar. Sua rejeição ao título se deu por entender que durante o regime militar a universidade havia expurgado professores, entre os melhores, por conta da aberração do decreto 477, afirmando que: "por tudo isso, seria uma incoerência se eu aceitasse a homenagem de uma universidade que se porta desta maneira e que admite lá dentro um interventor militar" (HOHFELDT, 1984, p. 41).

O livro de Veríssimo é dividido em quatro capítulos: As Credenciais, A Festa, O Carrossel e A Montanha. A maior parte da narrativa se passa na Embaixada da República do Sacramento, em Washington. Desse enredo, emerge todo contexto político, social e cultural da história, que, em muitas partes assemelha-se a momentos latino-americanos recheados por diferentes ciclos constitucionais em que se alteram democracias e autoritarismos.

"O Senhor Embaixador" integra a segunda parte da obra de Érico, que para ele é significativamente superior à primeira. Segundo um de seus biógrafos, Antônio Hohfeldt, o pensamento de Érico se distribui em diferentes personagens, de Pablo Ortega, "dividindo com William Godkin as atenções do leitor, ao lado com o professor Gris" (1984, p. 24). Sua ficção é de tal modo sediada na realidade histórico-social que Hohfeldt chega a escrever que se "pudéssemos imaginar um visitante extraterrestre a chegar em nosso planeta, devendo informar-se sinteticamente dos acontecimentos recentes, bastaria lhe indicar a ficção de Érico Veríssimo" (1984, p. 35).

O Embaixador da República de Sacramento de 1958 é, portanto, Don Gabriel Heliodoro Alvarado. 0 embaixador, pessoa da mais alta confiança e compadre do presidente da república, Juventino Carrera. Pela voz do personagem Orlando Gonzaga, diplomata brasileiro na capital dos EUA, é desses "embaixadores que, além de não pertencerem à carrière, dão 
um trabalho danado..." (VERÍSSIMO, 1971, p. 11). 0 então embaixador é filho de uma prostituta com um pai desconhecido, ele é o resultado de uma infância duríssima, testemunha ocular das crueldades dos regimes totalitários, assiste a execuções sumárias em massa e ao sofrimento humano de toda ordem - da violência direta dos assassinatos à violência estrutural das injustiças sociais de um país tipicamente latino-americano com graves desigualdades.

No segundo volume da autobiografia de Érico, Solo de Clarineta, o autor descreve a criação do romance: "O Senhor Embaixador me oferecia a oportunidade de estudar a estrutura política, econômica e social dessas republiquetas da América Central e do Sul e suas relações com o irmão maior e mais rico, os Estados Unidos" (VERÍSSIMO 1976, p. 62). Além disso, o "romance se prestaria também para mexer com um problema que sempre e preocupou: a participação do intelectual na política militante e, mais especificamente, numa revolução de caráter violento" (id. Ibid.), e segue:

Decidi que $O$ Senhor Embaixador devia ser um livro tão franco e desinibido quanto fosse possível fazê-lo. (Mais tarde, Wilson Martins havia de chamar-lhe com muita propriedade 'romance catártico') Como sempre, estava decidido a dar a mais ampla liberdade às minhas criaturas, embora esperasse que sua eventual rebeldia não acabasse por prejudicar meus objetivos primordiais (VERÍSSIMO, 1976, p. 62).

A primeira parte do livro, As Credenciais, apresenta o cenário da Embaixada, seus personagens principais e contextos, iniciando pela visão panorâmica de William Godkin, o Bill. Godkin é jornalista que cumpre 35 anos de trabalhos ao Amalgamated Press. Viúvo, especializado em América Latina (chefe do Beureau Latino-Americano). Bill, autor de uma dissertação intitulada "Radiografia das Ditaduras Latino-Americanas" e amigo de Orlando Gonzaga, primeiro secretário da embaixada do Brasil e ambos amigos de Pablo Ortega, jovem diplomata de Sacramento, primeiro secretário e filho da elite da ilha. Godkin conheceu Gabriel Heliodoro ainda nos tempos em que este era guerrilheiro junto ao "atual" presidente, que à época chefiava o movimento em que revoltou um batalhão do exército contra a ditadura de Don Antonio Maria Chamorro 
contra os federales - além de Bill ter feito outras várias andanças pelos países da região.

Em analogia à apresentação das credenciais do novo embaixador ao chefe de estado dos EUA, Veríssimo também descreve a personalidade a partir dos diálogos com o jornalista estadunidense. Godkin narra a primeira vez que viu Gabriel Heliodoro, estava ao lado de Juventino Carrera, na Sierra de la Calavera: "Era um de seus mais jovens e valorosos companheiros. Teria no máximo vinte e um anos...[...] (Fisicamente)... olhos vivos, escuros, dotados de uma perigosa força hipnótica. De todos os homens que conheci na cordilheira ao lado de Carrera, a fisionomia que mais fundo me ficou gravada na memória foi a desse Gabriel Heliodoro" (VERÍSSIMO, 1971, p. 20). 0 jornal do dia traz a descrição do embaixador, no dia em que assume a missão diplomática: nascido em 1903, 56 anos, e comentado por ambos, "cara atraente", mestiço com "traços indígenas". Apesar de ter registrado história de heroísmo ao afastar uma granada da gruta onde se escondia com o líder Carrera, salvando sua vida, também não teria concluído curso ginasial. Por fim, simpático, talvez desse um bom embaixador, com sangue indígena por parte de mãe, que era prostituta, e o pai desconhecido. Na sua autobiografia, Érico admite que Gabriel Heliodoro "era um parente remoto dos Cambarás, extraviado numa ilha no Mar das Antilhas" (VERÍSSIMO, 1976, p. 62), fazendo uma associação com a família cerne do Tempo e o Vento.

O embaixador, cuja família ficou em Sacramento, de fato externava magnetismo pessoal, poder de sedução. Isso não apenas sob sua amante, a linda Rosalía Vivanco de vinte e cinco anos, esposa de Pancho, servidor da embaixada, mas sobre todas e todos com quem interagia. Também é parte do cenário da embaixada o francês Michel Michel, valet de chambre e mordomo do embaixador, assim como o diplomata Ernesto Villalba, o Titito, segundo secretário, entendido de arte e bem informado de relações de bastidores.

De fato, no primeiro capítulo da obra, descrito como "As Credenciais" é nítida a demonstração de Gabriel Heliodoro, como um político com características que beiram ao populismo, movimento definido como um conjunto de práticas políticas que vigoraram em diversos países da América Latina, principalmente de 1930 a 1964, e que une liderança 
política baseada no carisma pessoal e na rede de clientelismo, somadas a um frágil sistema democrático.

Já, no segundo capítulo do texto, intitulado "A Festa", o protagonista do livro organiza uma "recepção" para algumas personalidades importantes de Washington, local onde iria residir o novo embaixador. Aqui, vale destacar o papel da secretária da embaixada, Clare Ogilvy ("La Ogilvita"), que conhecia as entranhas da embaixada desde os antigos embaixadores, até a chegada do atual representante da República do Sacramento. Em um dos diálogos com Bill, La Ogivita afirma que:

[...] Eu queria organizar uma recepção menor, limitada apenas à faixa latino-americana, alguns funcionários do Department of State, cronistas sociais e gente de imprensa. Seria mais barato e até mais divertido. Mas qual! Don Gabriel Heliodoro insistiu em fazer uma festa em grande estilo. Você sabe que temos mais de oitenta representações diplomáticas em Washington. (...) Convidamos todas! — Soltou uma risada, apertou o braço de Bill. — Queria que você visse o olhar de espanto, misturado com alegria e encanto, de Don Gabriel Heliodoro quando chegaram o embaixador de Gana e o do Iraque nos seus trajes nativos. Quase bateu palmas quando viu a embaixatriz da índia, num belo sari cor de maravilha. Nosso embaixador diverte-se como um menino num circo... (VERÍSSIMO, p. 136, 1985)

Nessa festa, em que representantes de diversos países e culturas se encontram, é possível perceber a sutil ironia de Veríssimo quanto à forma de se fazer "política" internacional e acordos com autoridades de países estrangeiros. 0 diálogo entre o jornalista estadunidense Godkin e o diplomata brasileiro Gonzaga abrem visões de mundo e críticas civilizatórias sagazes. Ambos debatem sobre as caricaturas da cultura estadunidense, opinião pública do país, papel da mídia ("este país se alimente da mitos dourados"), de modo crítico e ponderado, entre defeitos (como arrogância e racismo) e realizações (ao fazerem do seu país, um dos mais ricos e confortáveis do planeta) (VERÍSSIMO, 1971, p. 116-117). No mesmo capítulo, o tema ganha corpo quando o sacramentenho Pablo discute a dissertação da estadunidense Glenda Oremus sobre a história da republiqueta caribenha, onde Pablo sentencia: "Como boa americana alimentada desde a infância por histórias de bandidos e mocinhos, você procurou heróis absolutos e bandidos absolutos na História do meu 
país. A coisa não é tão simples assim. Você pintou seu quadro com cores primárias, em grandes chapas. 0 resultado foi um cartaz sem matizes" (idem, p. 129) - e a partir dali ele discorre sobre a complexidade do processo histórico e as contradições e paradoxos das personalidades de seu país. Esse trecho traz à lume também a interação dos interesses pessoais e sobreposições às necessidades estatais e políticas.

Também, entra em cena de modo mais veemente o professor da universidade federal da República de Sacramento, Leonardo Gris, opositor do governo de turno e ex-ministro da educação do governo que antecede o compadre do embaixador. Gris está exilado nos Estados Unidos, onde profere palestras sobre seu país - personagem chave para a problematização do intelectual na política, juntamente com Pablo (BORDINI, 2004). É amigo de Pablo, Godkin e Orlando. A universidade federal (ainda que Sacramento lembre mais um estado unitário que federativo) aparece do início ao fim como o espaço de resistência para os movimentos libertários, a luta pela democracia e a liberdade.

Posteriormente, na terceira parte, tem como título "O Carossel" - do poder, da diplomacia, das relações na embaixada. Vem à tona as dúvidas e conflitos internos de Pablo Ortega, personagem importante da obra que vive o dilema entre seguir o que a sua família de latifundiários. Acaba por admirar o próprio Gabriel Heliodoro:

[...] Gabriel Heliodoro? Bom, tudo me seria mais fácil se eu conseguisse odiá-lo, desprezá-lo ou, melhor ainda, não tomar conhecimento da existência dele. Mas o tipo é insinuante, envolvente, e cada vez que me sinto inclinado a gostar dele, não posso evitar o pensamento de que, nessa hora, estou atraiçoando mais uma vez Maestro Natalicio e seu povo.

- Acho que a amoralidade desse tipo tem para você um forte elemento de fascínio.

(VERÍSSIMO, 1985, p.219).

Esse parágrafo faz a relação com a última parte da obra, "A Montanha", em que Gabriel Heliodoro retorna para República do Sacramento para defender o então ditador que ele apoiava, mesmo sabendo que a "guerra" estava perdida. Nesse contexto, o protagonista acaba preso e é julgado por seus "crimes", sendo que o próprio Pablo Ortega será seu advogado 
de defesa. E o Senhor Embaixador sabia seu fim: "O preço de uma vida violenta, meu amor, é uma morte violenta" - disse ele à amante Rosalía (VERÍSSIMO, 1971, p. 92).

Abaixo, apresenta-se algumas ponderações sobre poder e constitucionalização que estão implícitas no livro de Veríssimo.

\section{“O SENHOR EMBAIXADOR": AS REPRESENTAÇÕES SOBRE PODER E CONSTITUCIONALIZAÇÃO}

$\mathrm{Na}$ embaixada da ilha caribenha, no interior dos EUA, resta evidente o chamado "canto das sereias" enfrentado pelas pessoas que assumem o poder político (OST, 1999). A partir da sensação deste "poder", muitas pessoas começam a sentir a força que possuem sobre "o outro" e sobre sociedade.

Na obra "O Tempo do Direito", de François Ost, é retratado uma metáfora em que Ulisses, encantado pela narração de que, em determinado rochedo a beira das águas, haveriam sereias que cantavam uma canção fascinante decide ir ao encontro das mesmas. Entretanto, Ulisses pede à sua tripulação que tapem seus ouvidos com cera para não escutarem o canto e, também solicita que o amarrem ao mastro do navio para que ele não se lance ao mar, pois entende a força do encanto e que também sucumbiria. Dessa forma, Ulisses consegue voltar ao continente e revelar como é - de fato - a referida lenda (OST, 199, p. 269). É a partir desta metáfora que se explica, igualmente, o papel do constitucionalismo na amarração que se faz sob o exercício do poder político no Estado de Direito (VIEIRA, 2016, p. 126).

O livro "O senhor Embaixador" demonstra essas seduções que o poder emite, e que vários políticos dos diversos Estados estão submetidos. Deve-se igualmente atentar para o fato de que na contemporaneidade é necessário descobrir uma forma de (re)encontrar as "correntes" que prendiam Ulisses ao mastro do navio. Talvez essas correntes possam ser pensadas por novas reconfigurações da teoria dos freios e contrapesos, na qual um poder controla outro poder, desenvolvida por John Locke e Charles-Louis de Secondat, barão de la Brède e de Montesquieu (séculos 
XVII e XVIII); pela ideia da própria imprensa livre e sem censura ou pela ascensão da sociedade civil de movimentos por determinados direitos. Esses movimentos denominam o que se chama de globalização desde baixo: em outros termos, uma "alterglobalização" (HERRERA FLORES, 2009, p. 68) atenta às necessárias inter-relações entre o global e o local.

0 movimento de constitucionalização do direito passou por diversas alterações ao longo da história, sendo controvertido até mesmo à época, no zeitgeist em que surgem as primeiras Constituições (NASCIMENTO, 2011). O significado das Constituições modernas é basicamente estabelecer a limitação de poder e a proteção dos direitos e garantias fundamentais. Assim, considera-se o constitucionalismo moderno foi o iniciador das bases a que (ainda) está atrelado o constitucionalismo contemporâneo.

O constitucionalismo, passa por uma grande alteração no Pós-Guerra, surgindo o que alguns teóricos denominaram de "neoconstitucionalismo" (CARBONELL, 2005; 2007). Essa postura está relacionada mais a manifestações de movimentos da teoria crítica do direito contra os diversos positivismos. Contudo, há grandes divergências a respeito do tema, já que autores de várias correntes utilizam o termo. Como não é objeto do presente texto, aprofundar o tema, sublinha-se como forma de síntese, a posição de Lenio Streck:

[...] Durante a década de 90, aproximei-me dessa leitura acerca dos movimentos que marcaram o direito no segundo pós-guerra, porém, sempre marcada por uma profunda diferença: o modo como se pensava e se procurava dar soluções para o problema da interpretação do direito. No meu caso, minha filiação às teorias que redescobriram a hermenêutica ainda na primeira metade do século XX (no caso, a fenomenologia hermenêutica e a hermenêutica filosófica) sempre me colocou à margem de algumas das principais conclusões apuradas pela grande maioria dos teóricos do neoconstitucionalismo.

Na verdade, nunca consegui concordar com o modo de encarar a relação entre direito e moral ou o problema da interpretação e da aplicação do direito nos termos propostos pelo neoconstitucionalismo. Assim, se em um primeiro momento houve uma aproximação entre a minha proposta teórica e o neoconstitucionalismo, isso se deu muito mais por uma questão nominal (a palavra "neo", efetivamente, é sedutora) do que propriamente real (STRECK, 2018, p. 27). 
Streck prefere utilizar Constitucionalismo Contemporâneo (com iniciais maiúsculas), para se referir ao movimento que acarretou nas Constituições do segundo pós-guerra e que ainda estão presentes no contexto atual em que se discute o sentido da constitucionalização do direito (STRECK, 2018, 29).

A tensão originária entre o constitucionalismo e o poder permanece, assim como sua demanda por conter (regrar) "o poder político" que vive ébrio pelo "canto da sereia", concentrado nas funções tradicionais do legislativo, executivo e judiciário. Acerca disso, Ost questiona: poderia “Um povo pode usar grilhões para o futuro?" (OST, 1999, p. 273).

O que dá um tempero especial ao presente trabalho é a analogia da ficção do embaixador de Sacramento, pois Gabriel Heliodoro não pertence à carreira diplomática e é amigo leal do presidente, e de fato, em 2019 o presidente da república do Brasil indicar seu próprio filho a chefiar a embaixada brasileira junto aos EUA (BERTONI, 2019), demonstrando mais um elemento da sintonia da ficção publicada na década de 1960 com a facticidade contemporânea. No jargão "a vida imita a arte”, poder-se-ia ainda questionar a dimensão do fato contemporâneo trazer "requinte" patrimonialista do nepotismo.

Na República do Sacramento, cada ciclo constitucional segue o desenho estipulado pelo poder de turno, e não o que a teleologia do constitucionalismo estabelece, de o poder submete-se ao constitucionalismo - o que está na razão ontológica do Estado constitucional. Ademais, conforme a conveniência e o interesse do momento, fala-se em emendas à constituição, como o caso da emenda proposta para possibilidade de uma terceira eleição consecutiva de Juventino Carreira (fato que décadas depois acaba por suceder efetivamente em diversos países latino-americanos, como o Peru de Fujimori, Brasil de Fernando Henrique Cardoso, Argentina de Carlos Menem, mesmo a Bolívia de Evo Morales e Venezuela de Hugo Chávez). Em síntese, o que se passa em Sacramento é sincrônico aos desafios persistentes do Estado de Direito na América Latina.

Antes de responder juridicamente essas indagações, vale mencionar que este questionamento, está presente na obra "O Senhor Embaixador", em vários momentos, como segue: 
[...] esses ditadores latino-americanos são todos feitos do mesmo estofo. Mas ouça esta história edificante. Aproximava-se o fim do segundo mandato do Generalíssimo. Existia na nossa Constituição uma cláusula que proibia sua segunda reeleição. Mas Carrera tomara gosto pelo poder. Não só isso: sua "fábrica" de dinheiro seria destruída se um adversário fosse eleito. Um movimento de oposição esboçava-se no Congresso. 0 povo estava descontente. Havia inquietação nos meios intelectuais, principalmente na Universidade. Alguns jornais começaram a atacar o Governo. É evidente que Carrera devia ter pensado em impor ao eleitorado um candidato seu que, uma vez eleito, ele poderia manejar como um fantoche. Mas concluiu, parece, que seria perigoso correr o risco duma eleição normal. E que se faz numa situação dessas, minha prezada senhorita? Está claro que se inventa um perigo, se fabrica uma conspiração que torne necessárias medidas de exceção. E qual é a desculpa óbvia? A iminência dum golpe comunista. (VERÍSSIMO, 1985, p. 187-188)

[...] Pois bem. Poucos meses depois dessa visita, convocou-se uma Constituinte, que formulou uma nova Constituição, que foi em seguida adotada e três meses mais tarde realizavam-se eleições livres que fizeram o Dr. Júlio Moreno em 1949 o primeiro Presidente de nossa Terceira República (p.189).

- Moreno deu liberdade a todos os partidos. Libertou todos os prisioneiros políticos. Aboliu por completo a censura aos jornais. Determinou uma série de devassas em vários setores da administração anterior e exigiu que Carrera e seus sócios, ministros e afilhados explicassem perante a Justiça e o povo a origem de suas fabulosas fortunas. Mal começaram as investigações, o Generalíssimo (que, sentindo-se seguro até então, permanecera no país) tomou seu avião particular e fugiu com toda a família, buscando asilo na República Dominicana, junto de seu compadre Rafael Leonidas Trujillo. Ugarte fez o mesmo. Mas Gabriel Heliodoro ficou em Cerro Hermoso, escudado pelo prestígio do sogro e principalmente pela sua habilidade política. Portou-se como esses bichos que se fingem de mortos quando se sentem em perigo. E sobreviveu. (VERÍSSIMO, 1985, 190).

Percebe-se que Veríssimo traz a Constituição, percebida pelos "donos do poder" apenas enquanto um "instrumento" para manter o poder, atrelado às forças dominantes de determinado período histórico. Ele evidencia, a partir da sociologia constitucional, a tensão em movimento do poder e o constitucionalismo, os fatores reais de poder, conforme definiu Ferdinand Lassalle apresenta no discurso que virou livro "A essência da constituição" (LASSALLE, 2001). Logo, a Lei Fundamental era substituída quando ocorria alternância de governo ou mudança de poder. 
Retornando ao plano da filosofia política que moldou o constitucionalismo, percebe-se que o posicionamento clássico de teóricos como Locke defendem que "os homens podem estabelecer a forma de governo que lhes aprouver, tese que se apóia no facto de que ninguém poderia obrigar por contrato os seus filhos ou a sua posteridade". Um século mais tarde, Rousseau concordará com a ideia apresentada, em termos mais claros, ainda: “é absurdo (...) que a vontade coloque grilhões para o futuro, de forma que um povo é sempre senhor de mudar as suas leis, mesmo as melhores" (OST, 1999, p. 273). É necessário, ao menos, uma forma de minimizar a possibilidade de alteração sistemática do texto constitucional ou da própria Carta Fundamental, muitas vezes o "canto da sereia" impera dentro dos "poderes" de Estado.

Assim, ao encontro do que afirma o jurista belga, é necessário reservar lugar para uma mudança "metamórfica", que aprofunde o seu sentido, alargue o seu alcance e diversifique as suas manifestações. Para exemplificar essas colocações, pode-se citar o art. V da Constituição americana, pois o mesmo continha um parágrafo que proibia a instituição da escravatura (pelo menos até o ano de 1808). Foi preciso esperar a votação da 13. Emenda em 1865 para que a escravidão fosse abolida. A revisão ocorrida inscreve-se mais em uma continuidade do que em ruptura com as "promessas" do sonho americano (OST, 1999, 276-281). Daí que é necessário legitimar limites fundamentais ao poder de revisão e a própria instauração de uma nova ordem constitucional.

A resposta de Ost para as perguntas colocadas anteriormente é de que sim, é necessário colocar limites no ordenamento jurídico, reconduzindo o direito à sua função própria de regulador da tensão entre ordem e desordem. Como uma das formas práticas de solucionar essas tensões, ele traz a jurisprudência dos Tribunais Constitucionais, levados com cada vez maior frequência a validar os atos de poder e interpretações que envolvam a validação ou invalidação das normas infraconstitucionais. Em outras palavras o “(...) tempo metamórfico, único suscetível de manter fecunda a tensão entre ordem e desordem. Como sempre, é no presente que se tem de trilhar, na herança do passado, aquilo que ainda é necessário para que o futuro tenha sentido" (OST, 1999, p. 283). 
Ao encontro do que foi exposto por Ost, ainda é possível encontrar outras formas práticas de minimização da tensão entre o "poder" e o "direito", como as manifestações de grupos populares, que vêm crescendo vertiginosamente nas últimas décadas devido, principalmente, as novas tecnologias e as tecnologias de informação e comunicação. Já foi possível perceber em diversas partes do mundo que ocorreram influências diretas do povo nas decisões políticas, como por exemplo, é possível citar o movimento "ocupe Wall Street", em 2011; movimentos sociais no Egito, também em 2011; "as jornadas de junho de 2013 no Brasil", dentre outros. Em Sacramento, a opção pelas reações violentas ainda era a praxe corrente.

Dessa forma, é possível perceber que a defesa da "Constituição", ainda continua a ser um caminho para limitação de poder e, principalmente, de luta pelo princípio da dignidade humana. Além de certos aspectos constitucionais, abordados por Veríssimo, é evidente a relação com as relações internacionais no próprio título do livro, ora analisado, já as embaixadas funcionam como núcleos centrais de diálogo entre Estados e diferentes poderes. Estes aspectos serão abordados, abaixo.

\section{“O SENHOR EMBAIXADOR” PARA RELAÇÕES INTERNACIONAIS ENTRE ESTADOS UNIDOS E AMÉRICA LATINA}

O enfrentamento da "significação" social, como prefere o autor em detrimento ao vocábulo crítica, se expressa no campo das Relações Internacionais especialmente em duas de suas obras da maturidade, "0 Senhor Embaixador" e "O Prisioneiro". Se de um lado as injustiças sociais são severa e reiteradamente criticadas, bem como as estruturas que a sustentam são descritas, de outro há persistentes defesas pela paz mundial e pelos direitos humanos, assim como pela melhoria da compreensão intercultural, com ponderações e aprofundamentos argumentativos densos, em forma de dialética, nos diálogos dos seus personagens.

Para apresentar tal perspectiva crítica sobre as relações internacionais em Veríssimo, é importante fazer menção ao livro $O$ Prisioneiro, texto 
publicado no contexto da guerra do Vitenã, dedicado aos netos do autor que são estadunidenses e estavam chegando próximo a idade de se tornarem aptos ao serviço militar. A questão do racismo tem capítulo próprio na personalidade de um filho de negro com mulher branca que acaba por sofrer exclusão em ambos "grupos", encarnando a trajetória das tensões raciais nos EUA. Neste texto, Érico desenvolve diálogos profundos sobre paz e guerra - sobretudo na voz de uma professora, violada por militares em invasão anterior e defensora da paz, em ricos diálogos com militar de alto escalão (em que Clausevitz a Kant são citados) -, e a iminência da tortura de um membro da guerrilha de resistência local que saberia onde bombas haviam sido instaladas para atentados terroristas (VERÍSSIMO, 1978). Um cenário que conseguia bem refletir os dilemas da época, com propriedade e refinamento, entorno de temas que se mantém pertinentes.

Para discorrer elementos de Relações Internacionais à luz da obra "O Senhor Embaixador", inicialmente se demonstra o problema da verdade e dos juízos superficiais, que por fim são externados de modo sistemático nas relações interculturais que subsidiam também as relações diplomáticas e a política externa dos países, para na sequência se abordar aspectos da geopolítica, e, por fim, sobre tudo isso, evocar a transparência ética provocada pelo autor.

\section{A Crítica da Verdade e os juízos superficiais}

O debate sobre a verdade e os juízos superficiais são circularmente debatidos a fim de oportunizar uma visão mais complexa sobre a diversidade de matizes possíveis para o entendimento da sociedade e da política, dos processos históricos e seus paradoxos e contradições. É para isso que já nas primeiras páginas do romance a questão é problematizada, na voz do jornalista Godkin:

Isso que chamamos de fato não será uma espécie de iceberg, quero dizer, uma coisa cuja pare visível corresponde apenas a um décimo do todo? Porque a parte invisível do fato está submersa nas águas dum torvo oceano de interesses políticos e econômicos, egoísmos e apetites nacio- 
nais e individuais, isso para não falar nos outros motivos e mistérios da natureza humana, mais profundos que os do mar" (William Godkin, em VERÍSSIMO, 1971, p. 04).

Em sequência, a relação verdade, razão e paixão é novamente mencionada no diálogo entre Michel Michel e Gabriel Heliodoro, quando aquele admite que pensa em publicar livros de memórias sobre os embaixadores a quem serviu, à luz da mais rigorosa "verdade", e o embaixador problematiza " - Verdade? Mas o que é a verdade? Escreva o livro com paixão, homem! Porque a paixão é a verdade de cada um de nós” - diz Gabriel Heliodoro a Michel Michel (VERÍSSIMO, 1971, p. 29).

A crítica à verdade também transpassa uma reflexão crítica sobre os intelectuais e as universidades, na fala do professor Leonardo Gris a Pablo Ortega:

A verdade é que nós, os chamados intelectuais, seremos sempre péssimos homens de ação. Por alguma razão Stálin detestava esse tipo de gente. Repelimos os absolutos políticos e filósofos. Não aceitamos a ideia de que as coisas só possam ser pretas ou brancas, acreditamos nos matizes, na complexidade dos homens e de seus problemas. Tudo isso são pedras de tropeço no caminho da revolução, coisas que enfurecem os homens de pura ação revolucionária" [...] "Em suma, o intelectual é um condenado por definição" (VERÍSSIMO, 1971, p. 76).

No contexto político da República do Sacramento, aparece reiteradamente a instituição "Universidade Federal”, formado por seus professores e estudantes, que por diversos momentos são responsáveis por forjar um contraponto ao status quo. ("A Universidade é um ninho de agitadores", VERÍSSIMO, 1971, p. 135). Mas também os militares aderem aos movimentos revolucionários.

É nesse âmbito de entendimento sobre verdade que a narrativa é desenvolvida, sob diversos olhares, de modo a ter condições de contemplar a adequada complexidade e as diversas matizes que os fatos, suas interpretações e contextos, com seus paradoxos e contradições, sobre o embaixador, a República de Sacramento e seu devir histórico. E também é dessa maneira portanto que as Relações Internacionais são compreendidas. 


\section{A Crítica das Relações Internacionais}

A perspectiva crítica sob o viés das Relações Internacionais em Érico é adensada em sua vivência no circuito diplomático e Washington. Importa antecipar que ele não é um antiamericanista. Ponderado, o autor percebe as fortalezas e as fragilidades da "civilização" estadunidense, e expressa problemas pertinentes na relação dos EUA com o resto do mundo, em especial, no "Senhor Embaixador", com a América Latina. "Quem são os americanos para estabelecerem padrões absolutos para a humanidade? Super-homens? Deuses?” (pela voz de Orlando Gonzaga, em VERÍSSIMO, 1971, p. 13).

Na mesma linha, problematiza os elementos da pré-compreensão para as condições de interpretação dos contextos. "Como poderia um estadista puritano compreender a América Latina?" (VERÍSSIMO, 1971, p. 08). Dessa maneira, pode-se perceber uma problematização importante se tomar em conta o papel do Dasein, o ser-aí, heideggeriano (HEIDEGGER, 1988) na compreensão da verdade em Gadamer (1997).

Na perspectiva das Relações Internacionais, duas personagens estadunidenses chamam atenção, Clare Ogilvy (secretária da embaixada de Sacramento nos EUA) e Glenda Doremus (acadêmica que fizera dissertação sobre $A$ República de Sacramento). Clare, conhecida como "La Ogilvita”, é a engrenagem que faz mover a embaixada, a representação do pragmatismo estadunidense ("Mas com alma!" - VERÍSSIMO, 1971, p. 33), ombro de consolo às lamúrias dos sacramentenhos da embaixada e que ao mesmo tempo tempera suas traduções conforme lhe parece mais adequado - como expressa durante a festa oferecida pelo Embaixador. Ao passo que Glenda manifesta a visão do americano mediano, racista e preconceituosa, narra e descreve a América Latina e Sacramento pelo maniqueísmo superficial. Conforme lhe disse Pablo Ortega, "você procurou heróis absolutos e bandidos absolutos na História do meu país. A coisa não é tão simples assim. Você pintou seu quadro com cores primárias, em grandes chapadas. 0 resultado foi um cartaz sem matizes" (VERÍSSIMO, 1971, p. 129).

Clare e Glenda são duas matizes bem marcadas da representação estadunidense para as Relações Internacionais, de um lado, em Clare, 
uma capacidade, força e pragmatismo resolutivo, e de outro, em Glenda, a expressão de juízos interculturais superficiais e de pretensão colonialista, onde ignorância imposta pelos limitados horizontes implica em arrogância com relação à diferença interpretada como ameaça, e profunda falta de empatia.

Um terceiro personagem estadunidense é o jornalista William Godkin, chefe do Bureau latino-americano do Amalgamated Press, conhecedor da América Latina e de profunda empatia com o que passa ao sul do continente, sensível para perceber a complexidade dos jogos de poder e seus povos - um viés mais sofisticado do olhar estadunidense sobre América Latina.

Nesse diapasão, em diferentes contextos aparece os interesses financeiros estadunidenses sobrepondo-se aos demais, a política à serviço do grande capital, e as contradições da política externa dos EUA em defender liberdade e direitos civis e apoiar, simultaneamente regimes antidemocráticos e violadores de direitos de seus povos.

Acerca dos sentimentos controversos dos povos latino-americanos com os estadunidenses, o embaixador a caminho da Casa Branca expressa bem a ambivalência:“(...), um dia escarrei na bandeira dos Estados Unidos. Escondido atrás de árvores, muitas pedras atirei em patrulhas de soldados gringos. Com essas mãos que estás vendo, escrevi a carvão em muito muro: Americanos peros sucios. E agora, Pablo, aqui vou como embaixador de meu país a caminho da Casa Branca. Não é fantástico?" (Gabriel Heliodoro a Pablo Ortega, VERÍSSIMO, 1971, p. 51). Antes de chegar a Casa Branca, pede para ir ao memorial de seu admirado Abraham Lincoln. Ao chegar no memorial, pensou: "Aqui estou, Mr. Lincoln! Sou aquele indiozinho sujo de Soledad del Mar, lembra-se? Na Casa Branca, o Presidente dos Estados Unidos me espera. Mostrei a todos esses filhos da puta que tenho cojones" (VERÍSSIMO, 1971, p. 54) - na clara expressão também da representação de um caudilho latino-americano. Tal percepção sobre as relações entre EUA e América Latina também estão amarradas numa visão ética. 


\section{A Crítica ética}

A visão ética expressa no espiral de pensamentos e diálogos registrados no romance partem de premissas da justiça e paz, o que se anuncia nas primeiras páginas:

Ao desintegrarem o átomo, os cientistas do nosso século desintegraram também a semântica e até a ética. Quem é que sabe hoje com certeza absoluta o sentido das palavras que usamos com tão leviana frequência como liberdade, paz, direito e justiça? Quanto ao Palavrão, verdade ... que bicho é esse? Quantas verdades existem no mundo de nossos dias? Conheço tantas... A da Casa Branca, A do Kremlin. A do Vaticano. A do Wall Street. A da Broadway. A da United States Steel Corporation. A da A.F.L. Sim, convém não esquecer a da Madison Avenue, talvez a mais fantástica de todas" (VERÍSSIMO, 1971, p. 04).

O anúncio da preocupação ética desde o início do romance é pormenorizado, detalhado e ampliado, ponto a ponto, ao longo de todo o texto, incluindo o papel sobre decisões das distintas instituições acima enumeradas, vinculadas ao mercado (Wall Street), à indústria cultural (Broadway) e à mass media (Madison Avenue).

E diante de todas essas tensões políticas, golpes e revoluções, o valor fundante da vida humana é reafirmado, conforme expresso no episódio em que um presidente ficara sob ataque dos revolucionários, liderados pelo então presidente e apoiado pelo ora embaixador.

Não quero o sacrifício de ninguém. Detesto a ideia da morte inútil. Deponham armas e façam depois o que entenderem: entreguem-se ou fujam. Eu os liberto de qualquer compromisso para com o meu governo. Obrigado teria dito o presidente da república de Sacramento, Julio Moreno, durante a ocupação dopalácio presidencial aos seus apoiadores mais próximos (VERÍSSIMO, 1971, p. 72-73).

É no âmbito desta problematização sobre a verdade, a relação dos Estados Unidos e a América Latina, sob diferentes lentes, voltado ao refinamento dos referenciais éticos das relações humanas, que o romance de Érico se estrutura, e ensina, ao Direito e às Relações Internacionais. 


\section{CONSIDERAÇõES FINAIS}

À luz de uma perspectiva crítica do constitucionalismo, percebe-se que o romance "O Senhor Embaixador" de Érico Veríssimo evidencia importantes dimensões sobre a sociologia constitucional latinoamericana, com suas com suas devidas tensões e proeminentes desafios, assim como alguns dos diversos matizes que pavimentam a as relações internacionais entre Estados Unidos e os países latino-americanos. 0 romance mostra-se fértil também para discussões acerca dos arranjos de poder no interior de um Estado e como estes repercutem no delineamento de sua política externa. No caso específico, destacando-se a relevância da chefia da missão diplomática dos países latino-americanos em Washington, ou seja, por quem e como se conduz a interação com o país mais rico do planeta, numa relação tensa que é simultaneamente de admiração e de resistência.

No presente trabalho, procurou-se demonstrar a crítica social, política e filosófica por meio da literatura, que se desdobram na funcionalidade e na disfuncionalidade do Direito - do fato à ficção não apenas da obra em destaque, mas também de outros livros do mesmo autor. Ingressa-se especificamente dentro das áreas de direito constitucional e relações internacionais, pois se apresenta um núcleo central de teoria da constituição relacionado às formas de limitação das funções estatais e as diferentes formas de "sedução" a que estão submetidos os representantes do povo e que ocupam importantes cargos públicos. Posteriormente, questões centrais para as Relações Internacionais, a crítica da verdade e os juízos superficiais, da relação EUA-América Latina e a questão da ética.

"O Senhor Embaixador" é um registro da facticidade dos jogos de poder que se passam na América Latina e suas nefastas consequências as suas populações empobrecidas; o romance é uma crônica da turbulenta relação do Direito e da Democracia da região e sobre o quão necessário se faz a resiliência do constitucionalismo em ciclos históricos de retrocesso. "O Senhor Embaixador" é um alerta sobre o "canto das sereias" do poder, do canto que não cessa. "O Senhor Embaixador" também é uma afirmação sobre a pertinência crítica da relação Direito e Literatura. 


\section{REFERÊNCIAS}

BERTONI, Estêvão. 0 que faz o Embaixador nos EUA. E o caso Eduardo Bolsonaro. Disponível em <https://www.nexojornal.com.br/expresso/2019/07/12/0-quefaz-o-embaixador-nos-EUA.-E-o-caso-Eduardo-Bolsonaro>. 12 jul. 2019.

BORDINI, Maria da Glória. A materialidade do sentido e o estatuto da obra literária em 0 senhor embaixador, de Erico Veríssimo. In: Zilberman, Regina et al. As pedras e o arco: fontes primárias, teoria e história da literatura. Belo Horizonte: Editora da UFMG, 2004.

CARBONELL, Miguel (ed). Neoconstitucionalismo(s). 2. ed. Madrid: Editorial Trotta, 2005.

CARBONELL, Miguel (Ed). Teoría del neoconstitucionalismo. Ensayos escogidos. Madrid: Editorial Trotta, 2007.

GADAMER, Hans-Georg. Verdade e Método I. Traços fundamentais de uma hermenêutica filosófica. 5. ed. Petrópolis: Vozes, 1997.

HEIDEGGER, Martin. Ser e tempo. Petrópolis: Vozes, 1988.

HERRERA FLORES, Joaquín. A (re)invenção dos direitos humanos. Florianópolis: Fundação Boiteux-IDHID, 2009.

HOHLFELDT, Antônio. Érico Veríssimo. 3. Ed. Coleção Esses Gaúchos. Porto Alegre: Amrigs, 1984.

LASSALLE, Ferdinand. A essência da Constituição. Prefácio de Aurélio Wander Bastos. 6. ed. Rio de Janeiro: Editora Lumen Juris, 2001.

NASCIMENTO, Valéria. 0 tempo das reconfigurações do constitucionalismo. Os desafios para uma cultura cosmopolita. São Paulo: LTr, 2011.

NASCIMENTO, Valéria; MENDONÇA, Fernanda. Um Rio Chamado Tempo, Uma Casa Chamada Terra: contribuição de Mia Couto para o direito na literatura. Anamorphosis - Revista Internacional e Literatura, v. 4, n. 1, janeiro-junho 2018, p. 279-297. 
OST, François. Contar a lei: as fontes do imaginário jurídico. São Leopoldo: Ed. da Universidade do Rio dos Sinos, 2004.

OST, François. 0 tempo do direito. Tradução de Maria Fernanda Oliveira. Lisboa: Instituto Piaget, 1999.

SCHWARTZ, Germano. A Constituição, a literatura e o direito. Porto Alegre: Livraria do Advogado, 2006.

STRECK, Lenio Luiz. (Neo)constitucionalismo. In: ALVIM, Arruda Alvim; LEITE, George Salomão; STRECK, Lenio. Curso de direito constitucional. Florianópolis: Tirant lo Blanch, 2018.

STRECK, Lenio; VIEIRA, Gustavo Oliveira; GONZAGA, Sergius. O Senhor Embaixador. TVE/RS, "Direito \& Literatura". 64º programa. Disponível em: < https://vimeo.com/17802454>. Porto Alegre, 14 mar. 2010.

VERÍSSIMO, Érico. Caminhos cruzados. São Paulo: Companhia de Bolso, 2016.

VERÍSSIMO, Érico. Incidente em Antares. 49. ed. Porto Alegre: Globo, 1997.

VERÍSSIMO, Érico. o prisioneiro. Porto Alegre: Globo, 1978.

VERÍSSIMO, Érico. 0 senhor embaixador. Porto Alegre: Globo, 1971.

VERÍSSIMO, Érico. 0 tempo e o vento. 0 continente I. 34. ed. São Paulo: Globo, 1997-a.

VERÍSSIMO, Érico. Solo de clarineta: memórias. 2ovol. Porto Alegre: Globo, 1973-1976.

VIEIRA, Gustavo Oliveira. Constitucionalismo na mundialização: desafios e perspectivas da Democracia e dos Direitos Humanos. Ijuí: Unijuí, 2015.

VIEIRA, Gustavo Oliveira. A Formação do Estado democrático de direito: o constitucionalismo na emergência da sociedade civil. Ijuí: Unijuí, 2016. 
Artigo recebido em: 9-9-2019

Aprovado em: 17-12-2019

\section{Gustavo Oliveira Vieira}

Doutor em Direito pela Universidade do Vale do Rio dos Sinos (2012), com período sanduíche na University of Manitoba, Canadá (bolsista ELAP); mestre em Direito pela Universidade de Santa Cruz do Sul, UNISC, (2005); professor Adjunto do Curso de graduação e do mestrado em Relações Internacionais da Universidade Federal da Integração Latino Americana (UNILA) em Foz do Iguaçu, Paraná, Brasil. Coordenador do projeto de extensão "Paradiplomacia para Cooperação (Trans)Fronteiriça: fomentando políticas de integração para o bem viver" e do projeto de pesquisa "Desafios da Integração (Trans)Fronteiriça: construção da paz e dos direitos humanos na ressignificação das fronteiras". E-mail: gustavo.vieira@unila.edu.br

\section{Valéria Ribas do Nascimento}

Doutora em Direito Público pela Universidade do Vale do Rio dos Sinos (UNISINOS), com período de pesquisa na "Universidad de Sevilla" (US); pósdoutora pela Pontifícia Universidade Católica do Rio Grande do Sul (PUCRS); mestre em Direito Público pela Universidade de Santa Cruz do Sul (UNISC); professora do Programa de Pós-Graduação em Direito da UFSM; professora Associada do Departamento de Direito da UFSM. Coordenadora do Núcleo do Direito Constitucional (NDC) da Universidade Federal de Santa Maria (UFSM), com bolsa de fomento do CNPQ/CAPES Edital Chamada MCTI/CNPq/MEC/ CAPES n. 07/2011. E-mail: valribas@terra.com.br

Universidade Federal da Integração Latino-Americana, ILAESP-UNILA.

Parque Tecnológico Itaipu. Jardim Itaipu. 85867900 - Foz do Iguaçu, PR - Brasil 